\title{
A stabilized maternal mortality rate estimator for biased skeletal samples
}

\author{
Clare McFAdDEN ${ }^{1 *}$, Britta VAN Tiel ${ }^{1}$, Marc F. OXenham $^{1,2}$ \\ ${ }^{1}$ School of Archaeology and Anthropology, Australian National University, Canberra, ACT 2601, Australia \\ ${ }^{2}$ Department of Archaeology, School of Geosciences, University of Aberdeen, Aberdeen AB24 3UF, United Kingdom
}

Received 8 March 2020; accepted 5 May 2020

\begin{abstract}
This paper seeks to provide a stabilized (i.e. less vulnerable to differences in sex representation) equation for estimating maternal mortality for biased skeletal samples. The stabilized equation is developed and tested on the United Nations data used to develop the original method (McFadden and Oxenham, Current Anthropology, 60(1), 141-146), and is applied to 16 bioarchaeological samples from mainland Southeast Asia. First-order correlations and basic descriptive statistics were applied to the data. The stabilized equation was comparable in accuracy to the original equation. When applied to bioarchaeological samples, it proved to be advantageous where the sex ratio differed by more than 0.15 in either direction (i.e. more females or more males). The stabilized equation is an improvement over the original equation for samples that exhibit sex bias that is randomly distributed by age. This method extends the potential applications of the maternal mortality estimator.
\end{abstract}

Key words: sample bias, fertility, maternal mortality, childbirth, pregnancy

\section{Introduction}

Childbirth poses a significant risk to many women today, as it has done throughout human history. Historical records indicate that in the 18th and 19th centuries, women experienced up to a $1 \%$ chance of dying during or shortly after childbirth (Loudon, 2000). Today, women in socioeconomically disadvantaged countries, regions and communities, are still faced with a high risk of up to 175 in 25000 deaths per births $(0.7 \%)$, despite their more advantaged counterparts experiencing risks as low as 1 in $25000(0.004 \%)$, and only 3 in 25000 on average $(0.012 \%)$ (WHO, 2018).

Looking past the present and beyond the historical record, McFadden and Oxenham (2019) developed a measure of maternal mortality based on age-at-death data derived from skeletal remains, permitting the opportunity to learn more about the maternal experience in ancient populations. This measure was noted to be a relative measure only, as it was developed using United Nations (2017) data from the 1990s, which were heavily skewed towards low maternal mortality rates (MMRs) and were unlikely to represent the high end of the range of MMRs experienced in the past. The original McFadden and Oxenham (2019) equation for the MMR is:

$$
\mathrm{MMR}=333.33 \times \frac{d_{F 20-24}}{d_{M 20-24}}-76.07
$$

\footnotetext{
* Correspondence to: Clare McFadden, School of Archaeology and Anthropology, 44 Linnaeus Way, Actonm ACT 2601, Australia. E-mail: clare.mcfadden@anu.edu.au

Published online 4 August 2020

in J-STAGE (www.jstage.jst.go.jp) DOI: 10.1537/ase.2005051
}

where $d_{\mathrm{F} 20-24}$ is the number of females who died aged 20-24 years and $\mathrm{d}_{\mathrm{M} 20-24}$ is the number of males who died aged 20 24 years. The MMR is defined as the number of maternal deaths per 100000 births, with maternal deaths encompassing women who die during pregnancy, childbirth, or within 42 days of giving birth.

The application of a maternal mortality estimator has the potential to inform our understanding of a variety of biological, social, and environmental factors that may contribute to maternal health and death. Biologically, it is recognized that women of short stature may suffer increased risk of obstetric complications due to cephalopelvic disproportion (Möller and Lindmark, 1997; Montgomery et al., 2014) and further genetic factors, including head size and pelvic shape of the mother (Fischer and Mitteroeker, 2015), may also contribute to the risk profile. Those of poor pre-existing health (particularly malnutrition) may be at increased risk of maternal death through haemorrhaging and infection (New and Wirth, 2015; Rush, 2000). A case-by-case assessment is essential as conditions such as thalassaemia cause an increased risk of death through bleeding, amongst other factors (Petrakos et al., 2016), while providing a silver lining in terms of a potentially decreased risk of death from malarial infection (Clegg and Weatherall, 1999). Currently, combined social factors, such as care and social status, can significantly contribute to an individual's maternal risk profile (Hanson et al., 2015; Walraven and Weeks, 1999), as they undoubtedly did since the emergence of social stratification and increasing disparity in access to food, housing, medical treatment, and so forth. Environmentally, a range of factors from pathogen exposure (with puerperal fever being the most notorious example; see Loudon, 2000) to climate change (Barreca and Schaller, 2020) may influence maternal morbidity and mor- 
tality risks. Demographic consequences are highly variable, as maternal mortality, infant mortality, and fertility are related in complex ways, with high fertility being a cause of high maternal and infant mortality, but conversely high maternal mortality decreasing fertility. Finally, such insights add to the narrative of the female experience of day-to-day life over the past several millennia.

Through preliminary applications of the McFadden and Oxenham (2019) maternal mortality estimator, it was observed that the method relied on equal, or close to equal, representation of males and females, otherwise the overrepresentation of either in the childbearing age group may be a product of the overrepresentation of males or females across all age groups. In this paper, a stabilized equation (i.e. one that is less susceptible to differences in the representation of males and females) for biased skeletal samples is developed and tested on the United Nations (2017) data used to develop the original method, and on 16 bioarchaeological samples to evaluate differences between iterations of the method and the utility of the stabilized equation.

\section{Materials and Methods}

As noted, through preliminary applications of the method it was observed that the accuracy of the McFadden and Oxenham (2019) equation may be undermined where males or females were overrepresented in the sample as a whole. It was hypothesized that the maternal mortality estimator could be stabilized by dividing the number of deaths in the childbearing years by the total number of deaths for both females and males. In this case, ages 20-29 years were used as this best fits the target bioarchaeological data; however, McFadden and Oxenham (2019) reported success with intervals of both 20-24 years and 20-34 years, and the equation may be adapted again to utilize these categories. An initial linear regression, as per McFadden and Oxenham (2019), of the MMR on the ratio of proportionate deaths aged 20-29 years of females to males was performed. Both the correlation between the stabilized ratio and MMR and the regression equation were very similar to the original (see Results). To facilitate ease of use of the estimator, the capacity for the existing regression equation to accurately estimate the MMR using the stabilized ratio was tested. The revised equation applied was:

$$
\begin{aligned}
& \text { Stabilized MMR } \\
& =333.33 \times\left(\frac{d_{F 20-29}}{d_{F \text { total }}} \div \frac{d_{M 20-29}}{d_{M \text { total }}}\right)-76.07
\end{aligned}
$$

The preliminary linear regression and the new equation were applied to the data previously used by McFadden and Oxenham (2019) to evaluate differences between the original and stabilized estimators. One country (Brunei Darussalam) had to be excluded due to unavailability of data, which reduced the sample size from 75 to 74 . Descriptive statistics and first-order correlations were performed. Both the original and stabilized ratios were applied to 16 samples from mainland Southeast Asia to assess the estimators when each one was applied to the bioarchaeological data. Fourteen of these samples were the subject of previous palaeodemographic evaluation based on the rate of natural population increase estimator (McFadden et al., 2018). Further review of the literature identified four additional samples with sufficient data for inclusion in this study. Age at death for these samples was as reported in the original studies unless otherwise noted.

\section{Results}

When applied to the United Nations (2017) data from McFadden and Oxenham (2019), the stabilized equation provided a comparable correlation $(r=0.884)$ to the original method $(r=0.894)$. The difference between the two correlation coefficients was calculated using the Fisher $r$-to- $z$ transformation and found to be statistically insignificant $(P=0.39$, one-tailed). Further descriptive statistics for the United Nations (2017) data are given in Table 1, including the slope and intercept for each linear regression analysis (note that the slope and intercept in the equation differ from those reported in Table 1, as the equation was solved for $x$ in order for the MMR to become the outcome variable). This shows from a theoretical perspective that there is little difference between the two ratios in terms of accuracy or distribution. As such, the original equation can be used with the stabilized ratio for the sake of simplicity and consistency.

However, there is indeed a substantial distinction between the ratios from an applied or practical perspective. The original and stabilized maternal mortality rate estimates for 16

Table 1. Descriptive statistics and first-order correlations for maternal mortality rate (MMR) and the original and stabilized estimators

\begin{tabular}{lccc}
\hline & MMR & $\begin{array}{c}d_{\mathrm{F} 20-24}: d_{\mathrm{M} 20-24} \\
\text { original estimator }\end{array}$ & $\begin{array}{c}d_{\mathrm{F} 20-29} / d_{\mathrm{F}}: d_{\mathrm{M} 20-29} / d_{\mathrm{M}} \\
\text { stabilized estimator }\end{array}$ \\
\hline$n$ & 74 & 74 & 74 \\
Range & $4.50-550.25$ & $0.10-2.35$ & $0.21-1.66$ \\
Mean & 53.45 & 0.40 & 0.45 \\
SD & 81.88 & 0.31 & 0.23 \\
Correlation with MMR & & 0.89 & 0.88 \\
$95 \%$ confidence interval & & $0.84-0.93$ & $0.82-0.93$ \\
Slope & & 0.0030 & 0.0024 \\
Intercept & 0.2282 & 0.3194 \\
\hline
\end{tabular}


Table 2. Original and stabilized maternal mortality rates (MMRs) for 16 bioarchaeological samples

\begin{tabular}{llccc}
\hline \multicolumn{1}{c}{ Site/sample } & \multicolumn{1}{c}{ Data source } & $\begin{array}{c}\text { Original } \\
\text { estimator }\end{array}$ & $\begin{array}{c}\text { Stabilized } \\
\text { estimator }\end{array}$ & $\begin{array}{c}\text { Ratio of total } \\
\text { females to males }\end{array}$ \\
\hline Non Ban Jak & Backley et al. (in press) & 313 & 299 & 1.04 \\
Man Bac & Domett and Oxenham (2011) & 114 & 152 & 0.83 \\
Con Co Ngua & Oxenham (2016) & 324 & 479 & 0.72 \\
Ban Lum Khao & Domett (2004) & 924 & 736 & 1.23 \\
Noen U-Loke & Tayles et al. (2007) & 129 & 158 & 0.88 \\
Non Nok Tha (early) $)^{\mathrm{b}}$ & Pietrusewsky (1974) & 91 & 283 & 0.46 \\
Non Nok Tha (late) ${ }^{\mathrm{b}}$ & Pietrusewsky (1974) & 524 & 457 & 1.13 \\
Khok Phanom Di & Tayles (1999) & 288 & 247 & 1.13 \\
Ban Chiang (early) & Pietrusewsky and Douglas (2001) & 591 & 838 & 1.73 \\
Ban Chiang (late) & Pietrusewsky and Douglas (2001) & 924 & 757 & 1.00 \\
Nong Nor & Domett (2001) & 257 & 257 & 0.59 \\
Ban Na Di & Domett (2001) & 72 & 175 & 1.00 \\
An Son & Willis (2015) & 924 & 924 & 1.05 \\
Ban Non Wat & Higham and Kijingam (2011) & 286 & 270 & 0.51 \\
Angkor Borei & Ikehara-Quebral et al. (2017) & 479 & 1014 & 0.71 \\
Nankuanlic & Pietrusewsky et al. (2016) & 257 & 391 & 464 \\
\multicolumn{2}{c}{ Standard deviation across samples } & 406 & 283 & \\
\hline
\end{tabular}

${ }^{\mathrm{a}}$ Young and young-mid adults used due to no numerical age groups.

${ }^{\mathrm{b}}$ 17-31 years used due to reporting of data.

c 20-35 years used due to reporting of data.

1200

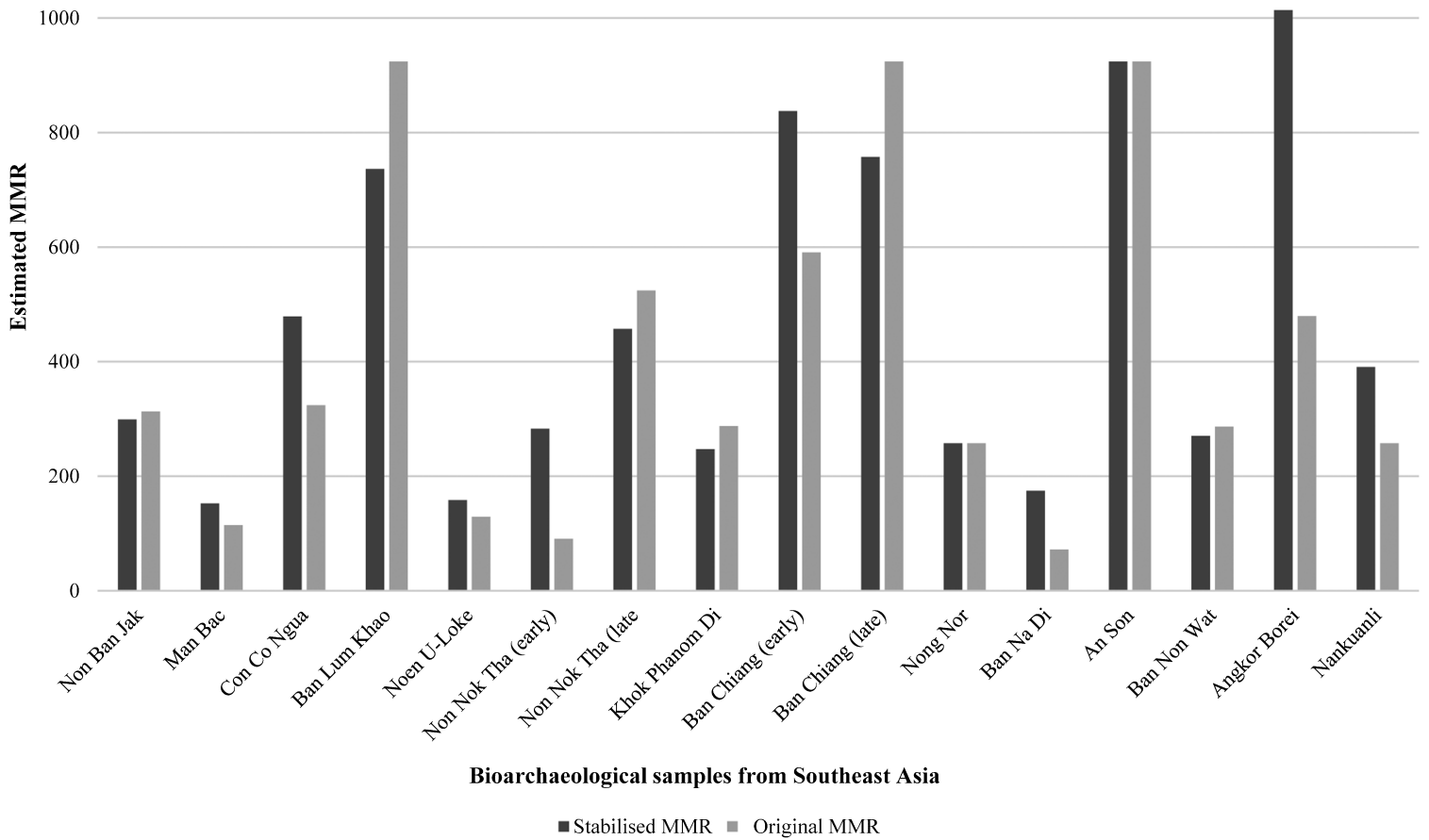

Figure 1. Comparison of stabilized and original maternal mortality rate (MMR) by site/sample.

bioarchaeological samples from Southeast Asia are provided in Table 2.

Linear regression of the ratio of total females to total males, and the proportionate difference between the original
MMR and stabilized MMR (determined by dividing the stabilized MMR by the original MMR), produced a correlation of $r=0.96(P<0.05)$, demonstrating that the more disparate the sex ratio (i.e. the further from 1 ), the greater the differ- 
ence between the original and stabilized MMRs. This confirms that the stabilized measure is preferable for samples where sex bias is evident in the skeletal sample. Particularly significant cases include Non Nok Tha (early), Ban Na Di, and Angkor Borei, where the stabilized MMRs are over twice that of the original estimates, and the Ban Chiang early and late samples, where the trend in MMR is reversed by applying the stabilized estimator. The stabilized and original MMR are visually compared in Figure 1.

\section{Discussion}

While the correlations for the original and stabilized ratios do not differ to a statistically significant extent, it is essential to note that the United Nations (2017) data are from the national level and therefore nearly all populations exceed the sample sizes encountered in bioarchaeology. As such, these data are very stable and we would not expect significant differences in the representation of the sexes. Indeed, the consistency in results between the original and stabilized ratios when applied to the United Nations (2017) data broadly reinforce the accuracy and stability of the MMR estimator. In contrast, bioarchaeological samples often exhibit differential representation of the sexes, as evidenced in Table 2. This can be for a number of reasons, such as variation in mortuary treatment or periods of warfare, or the cause may be unknown. Importantly, such cases are not rare (e.g. refer the Wellcome Osteological Research Database (2019) for further examples from English cemeteries spanning the Roman period to post-medieval) and thus the more stable proxy for maternal mortality is beneficial in application.

Applied to the 16 bioarchaeological samples from Southeast Asia, it is clear that differences between the stabilized and original estimates of maternal mortality are influenced by the ratio of total females to males in the sample. Those with ratios of 1.00-1.15 differed minimally, whilst those with ratios of $0.46-0.59$ varied significantly. This highlights the need for a stabilized equation for use in samples with a clear bias in representation by sex.

Notwithstanding, the application of the stabilized method assumes that the underrepresentation of either males or females will be normally distributed across all ages (i.e. age is a random variable). One such example is sex-selective infanticide, which may result in a substantially different sex ratio, but one that is randomly distributed across ages. There is bioarchaeological and historical evidence for this in Japan (Nagaoka and Hirata, 2007). However, in some cases the sex differential will not be randomly distributed across the age at death distribution, particularly for military and warfare-associated cemeteries. As such, the stabilized method only accommodates random sources of bias, such as differential mortuary practices or sex-selective infanticide, which impact all adult ages equally.

While the revised estimator remains a relative one, due to it being based on modern data which cannot fully replicate the maternal health and care conditions of the past, the application of the estimator to 16 archaeological samples from Southeast Asia has afforded the opportunity to provide a scale as guidance for the prevalence of maternal mortality. By calculating half a standard deviation (i.e. 283/2) either side of the mean (464) to produce the moderate (or middle) category (see results in Table 2), it is suggested that an MMR of 0-323 is low, 323-605 is moderate, and over 605 is high, based on the samples included in this study. Common sense should be applied to samples that sit close to the border of a category; for example, an assemblage with an MMR of 300 may be considered low to moderate. It should be noted that only one region, mainland Southeast Asia, is represented in this study and the scale may prove to be region specific when further applications of the estimator are tested.

\section{Conclusion}

Through application of the McFadden and Oxenham (2019) method for estimating maternal mortality, it was identified that the differential representation of males and females in a sample may create an artificial or erroneous result with the original estimator. An improved and statistically more robust estimator has been developed that stabilizes the method by incorporating the total number of females and males, thereby reducing its susceptibility to differences in male and female representation. Tested on the same data used to develop the original method, the stabilized estimator is shown to have comparable accuracy. By applying the methods to bioarchaeological samples it has been demonstrated that in samples with equal, or close to equal, representation of both sexes, the stabilized and original estimators produce very similar results. However, for biased samples, a significant difference was observed. In such cases, the stabilized estimator is preferable as it accommodates random overall sample bias. A scale for interpreting MMR estimates has been provided, though it is cautioned that this may prove to be region specific. Further studies in other regions of the world are needed to evaluate this.

\section{References}

Barreca A. and Schaller J. (2020) The impact of high ambient temperatures on delivery timing and gestational lengths. Nature Climate Change, 10: 77-82.

Buckley H., Domett K, Halcrow S., Pedersen L., Ward S., Ling N., O'Reilly D., and Shewan, L. (in press) An initial report on health and disease at Non Ban Jak. In: Higham C.F.W. and Kijngam A. (eds.), The Origins of the Civilization of Angkor. Vol. 7: The Excavation of Non Ban Jak. Fine Arts Department, Bangkok.

Clegg J.B. and Weatherall D.J. (1999) Thalassemia and malaria: new insights into an old problem. Proceedings of the Association of American Physicians, 111: 278-282.

Domett K. (2001) Health in Late Prehistoric Thailand. British Archaeological Reports, Archaeopress, Oxford.

Domett K. (2004) The people of Ban Lum Khao. In: Higham C.F.W. and Thosarat, R. (eds.), The Origins of the Civilization of Angkor, Vol. I: The Excavation of Ban Lum Khao. Thai Fine Arts Department, Bangkok, pp. 113-151.

Domett K. and Oxenham M.F. (2011) The demographic profile of the Man Bac cemetery sample. In: Oxenham M.F., Matsumura H., and Nguyen, K.T. (eds.), Man Bac: The Excavation of a Neolithic Site in Northern Vietnam. ANU Press, Canberra, pp. 9-20.

Fischer B. and Mitteroecker P. (2015) Covariation between human pelvis shape, stature, and head size alleviates the obstetric dilemma. Proceedings of the National Academy of Sciences of the USA, 112: 5655-5660. 
Hanson C., Cox J., Mbaruku G., Manzi F., Gabrysch S., Schellenberg D., Tanner M., Ronsmans C., and Schellenberg J. (2015) Maternal mortality and distance to facility-based obstetric care in rural southern Tanzania: a secondary analysis of cross-sectional census data in 226000 households. The Lancet Global Health, 3: e387-e395.

Higham C.F.W. and Kijngam A. (2011) The Origins of the Civilization of Angkor, Vol. 6: The Excavation of Ban Non Wat. Part IV: The Iron Age, Summary and Conclusions. Fine Arts Department of Thailand, Bangkok.

Ikehara-Quebral R.M., Stark M.T., Belcher W., Vuthy V., Krigbaum J., Bentley R.A., Douglas M.T., and Pietrusewsky M. (2017) Biocultural practices during the transition to history at the Vat Komnou cemetery, Angkor Borei, Cambodia. Asian Perspectives, 56: 191-236.

Loudon I. (2000) Maternal mortality in the past and its relevance to developing countries today. American Journal of Clinical Nutrition, 72: 241S-246S.

McFadden C. and Oxenham M.F. (2019) The paleodemographic measure of maternal mortality and a multifaceted approach to maternal health. Current Anthropology, 60: 141-146.

McFadden C., Buckley H., Halcrow S.E., and Oxenham M.F. (2018) Detection of temporospatially localized growth in ancient Southeast Asia using human skeletal remains. Journal of Archaeological Science, 98: 93-101.

Möller B. and Lindmark G. (1997) Short stature: an obstetric risk factor? A comparison of two villages in Tanzania. Acta Obstetricia et Gynecologica Scandinavica, 76: 394-397.

Montgomery A.L., Ram U., Kumar R., Jha P., et al. (2014) Maternal mortality in India: causes and healthcare service use based on a nationally representative survey. PLoS One, 9: e83331.

Nagaoka T. and Hirata K. (2007) Reconstruction of paleodemographic characteristics from skeletal age at death distributions: perspectives from Hitotsubashi, Japan. American Journal of Physical Anthropology, 134: 301-311.

New S. and Wirth M. (2015). Anaemia, pregnancy, and maternal mortality: the problem with globally standardised haemoglobin cutoffs. BJOG: An International Journal of Obstetrics \& Gynaecology, 122: 166-169.

Oxenham M.F. (2016) Bioarchaeology of Ancient Northern Viet- nam. BAR International Series 2781, British Archaeological Reports, Oxford.

Petrakos G., Andriopoulos P., and Tsironi M. (2016) Pregnancy in women with thalassemia: challenges and solutions. International Journal of Women's Health, 8: 441-451.

Pietrusewsky M. (1974) The palaeodemography of a prehistoric Thai population: Non Nok Tha. Asian Perspectives, 17: 125140.

Pietrusewsky M. and Douglas M.T. (2001) Intensification of agriculture at Ban Chiang: is there evidence from the skeletons? Asian Perspectives, 40: 157-178.

Pietrusewsky M., Lauer A., Douglas M.T., Tsang C.H., and Li K.T. (2016) Patterns of health in Early Neolithic and Iron Age Taiwan. Anthropological Science, 124: 117-133.

Rush D. (2000) Nutrition and maternal mortality in the developing world. American Journal of Clinical Nutrition, 72: 212S-240S.

Tayles N.G. (1999) The Excavation of Khok Phanom Di, a Prehistoric Site in Central Thailand. Volume V: The People. Reports of the Research Committee of the Society of Antiquaries of London.

Tayles N., Halcrow S., and Domett K. (2007) The people of Noen U-Loke. In: Higham C.F.W., Kijingam A., and Talbot S. (eds.), The Excavation of Noen U-Loke and Non Muang Kao. Thai Fine Arts Department, Bangkok, pp. 243-304.

United Nations (2017) UN Statistical Database. Available from https://unstats.un.org/databases.htm

Walraven G. and Weeks A. (1999) The role of (traditional) birth attendants with midwifery skills in the reduction of maternal mortality. Tropical Medicine \& International Health, 4: 527529.

Wellcome Osteological Research Database (2019) Museum of London. Available from https://www.museumoflondon.org. $\mathrm{uk} /$ collections/other-collection-databases-and-libraries/ centre-human-bioarchaeology/osteological-database

World Health Organization (2018) Fact Sheet: Maternal Mortality. World Health Organization, Geneva. http://www.who.int/ mediacentre/factsheets/fs348/en/

Willis A. (2015) The Bioarchaeology of An Sơn and Hòa Diêm: Biosocial Insights into Prehistoric Southern Vietnam. PhD dissertation, The Australian National University. 